\title{
On the geoelectric structure of major strike-slip faults and shear zones
}

\author{
Martyn Unsworth ${ }^{1}$ and Paul A. Bedrosian ${ }^{2}$ \\ ${ }^{1}$ University of Alberta, Edmonton, Alberta, Canada \\ ${ }^{2}$ GeoForschungsZentrum, Potsdam, Germany
}

(Received April 28, 2004; Revised October 1, 2004; Accepted October 14, 2004)

\begin{abstract}
Magnetotelluric imaging of the San Andreas Fault has shown that seismically-active segments are characterized by a zone of low resistivity in the upper crust. Similar resistivity features are observed on other major strike-slip faults, and may have a common origin in a region of fractured rock, partially or fully saturated with groundwater. Other strike-slip faults show possible zones of reduced resistivity in the mid and lower crust that may be related to zones of ductile shear. Additional MT surveys are required to elucidate the role of fluids in controlling the seismic behaviour of major faults, both in and below the seismogenic zone. A set of synthetic inversions show that MT data is sensitive to the geoelectric structure of a shear zone at mid-crustal depths.
\end{abstract}

Key words: Magnetotellurics, shear zones, strike-slip faults, earthquake cycle, San Andreas Fault.

\section{Introduction}

The physical processes occurring during the earthquake cycle in major strike-slip faults are the subject of current research (Hickman et al., 2004). Many of the geodynamic models proposed to explain the earthquake cycle and rupture process include both temporal and spatial variations in the fluid structure of the fault-zone (Byerlee, 1993; Blandpied et al., 1992). In these models, fluid enters the fault zone between earthquakes, raising the pore pressure and thus reducing the effective shear stress needed for rupture. In this manner fluids can facilitate both aseismic creep and earthquakes, such as the characteristic earthquakes observed at Parkfield (Johnson and McEvilly, 1995). While geological studies of exposed fault rocks give vital clues concerning the fluid content and strain distribution within inactive faults (Chester et al., 1993), studies of active faults are needed to fully understand the dynamic processes at work during the earthquake cycle. Geophysical studies are especially important in this regard as they can provide threedimensional images of fault-zone structure over a much wider area than can be sampled by drilling. Magnetotelluric (MT) studies have recently been used to study the resistivity structure of several major strike-slip faults. Since pore fluids significantly change the resistivity of a rock, this technique is an effective tool for studying the fluid regime in active faults.

In this paper, magnetotelluric studies of major strike faults are reviewed. The potential to study the deeper structure of these fault zones with magnetotellurics is then examined through a series of synthetic inversion tests that attempt to reproduce realistic field surveys.

Copy right(c) The Society of Geomagnetism and Earth, Planetary and Space Sciences (SGEPSS); The Seismological Society of Japan; The Volcanological Society of Japan; The Geodetic Society of Japan; The Japanese Society for Planetary Sciences; TERRAPUB.

\section{Magnetotelluric Studies of the San Andreas Fault}

Magnetotelluric studies of the San Andreas Fault in California have been undertaken at a number of locations on both creeping and locked segments (Eberhart-Phillips et al., 1990; Mackie et al., 1997; Unsworth et al., 1999, 2000; Bedrosian et al., 2002). At Parkfield, the San Andreas Fault is in transition from locked to continuously creeping and its seismic behaviour is characterized by sets of repeating earthquakes of various magnitudes. These include the well documented series of magnitude $M=6$ events (Bakun and Lindh, 1985) and also clusters of repeating microearthquakes (Nadeau et al., 1995). At Hollister, the San Andreas Fault is creeping, and frequent earthquakes are observed with an upper limit of magnitude $M=5$. The results of MT surveys at Parkfield and Hollister are summarized in Fig. 1. At both Hollister and Parkfield the resistivity models show a low resistivity zone coincident with the San Andreas Fault, termed the fault-zone conductor (FZC). At Hollister, this FZC extends to depths below 5-8 km. In contrast, the locked Carrizo segment is characterized by a less conductive fault zone structure (Mackie et al., 1997; Unsworth et al., 1999). These resistivity models can be interpreted by comparison with geological models of exhumed fault zones, such as that of Anderson et al. (1983), shown in Fig. 2. In this model a wedge of breccia that pinches out around 3$4 \mathrm{~km}$ depth characterizes the shallow structure of the fault. If the pore space in the breccia is filled with groundwater, then a low resistivity will be observed. The porosity and groundwater resistivity control the resistivity through the empirical Archie's Law (Archie, 1942). While the presence of clay minerals or serpentinite could contribute to the low resistivity, it appears that the degree of fluid saturation and fracturing is the most significant factor controlling the resistivity. This is confirmed by seismic surveys showing a zone of low velocity and elevated Poisson's ratio coincident with the fault-zone conductor in each location (Thurber et 
(a) Central creeping segment

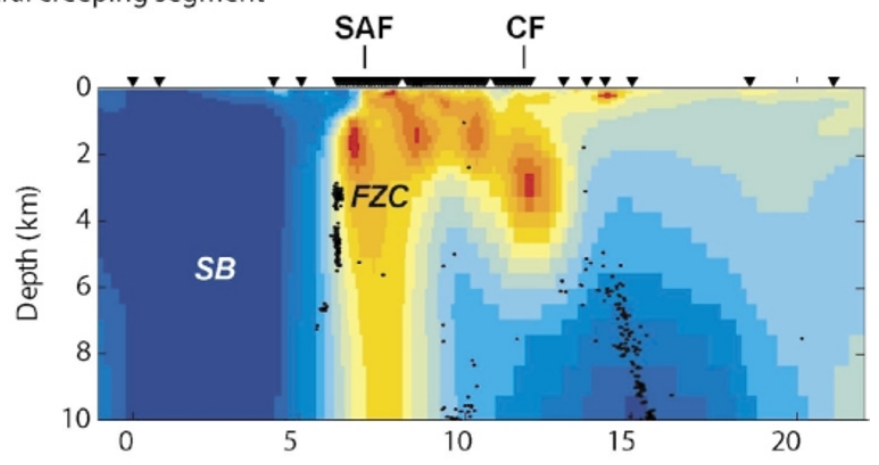

(b) Parkfield segment
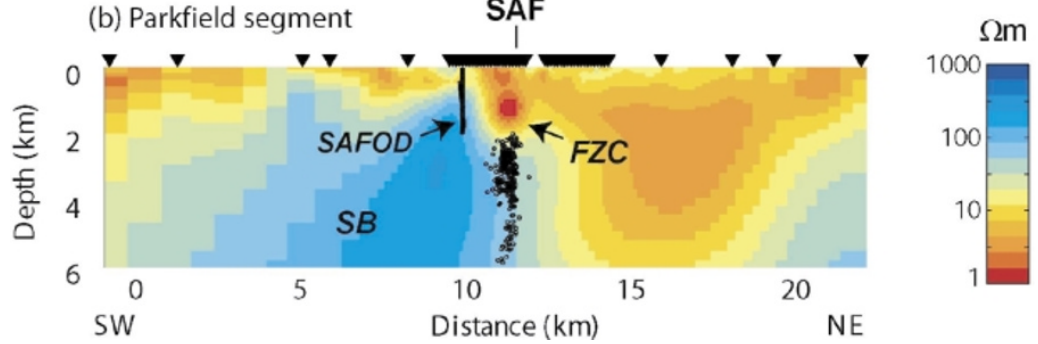

Fig. 1. Electrical resistivity structure of the San Andreas Fault at (a) Hollister where the fault creeps, (b) Parkfield, where the fault is in transition from being locked to creeping. $\mathrm{SAF}=$ San Andreas Fault; $\mathrm{CF}=$ Calaveras Fault; $\mathrm{SB}=$ Salinian block; SAFOD=San Andreas Fault Observatory at Depth; $\mathrm{FZC}=$ Fault-zone conductor. In each case seismicity is indicated by the black circles. Each model was derived from inversion of TE, TM and vertical magnetic field transfer functions using the inversion code of Rodi and Mackie (2001).

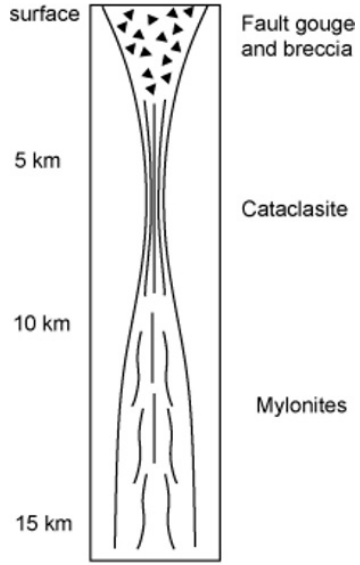

Fig. 2. Geological structure of major strike-slip faults, based on mapping of exhumed fault zones by Anderson et al. (1983). al., 1997; Thurber et al., 2003). If resistivity were controlled by conduction through phases such as clay or metallic minerals, a coincident reduction in seismic velocity and an increase in Poisson's ratio would not be expected. In the depth range 5-10 km, strike-slip motion produces cataclastic fault rocks formed by brittle deformation. In this part of the fault zone, decreased porosity due to lithostatic load generally results in a more modest resistivity anomaly within the fault zone. At greater depths, mylonites, formed during ductile deformation, comprise the shear zone.

The magnetotelluric studies on the San Andreas Fault suggest different geoelectric structures may be associated with different types of seismic behavior. It is possible that the magnetotelluric data are imaging the fluids that control the seismicity, i.e. the low resistivity of the seismicallyactive segments is due to the presence of the fluids that are

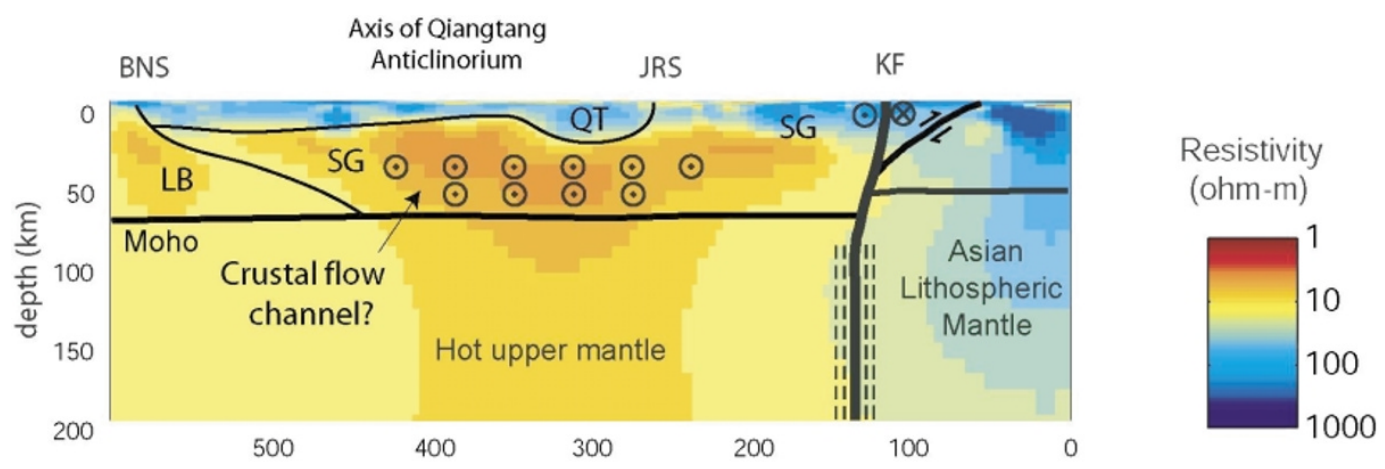

South

distance $(\mathrm{km})$

North

Fig. 3. Geoelectric structure of the northern margin of the Tibetan Plateau, taken from Unsworth et al. (2004). KF=Kunlun Fault; JRS=Jinsha River suture; BNS=Bangong-Nuijiang suture; $\mathrm{LB}=$ Lhasa Block; $\mathrm{SG}=$ Songpan-Ganze terrane; QT=Qiangtang Terrane. Note that the Kunlun Fault is coincident with a major change in the resistivity of the lithosphere, corresponding to a change in rheology. 
responsible for creep and repeating earthquakes through the mechanisms similar to those suggested by Byerlee (1993) and Blandpied et al. (1992). The MT data also image aquifers away from the San Andreas Fault, and pathways may exist for fluids to enter the fault zone from the side. For example at Parkfield, the east wall of the San Andreas Fault has a low resistivity for at least $10 \mathrm{~km}$ to the east (Unsworth et al., 2000). The idea that a fluid source in this region could control seismic activity was first suggested by Irwin and Barnes (1975). They noted that locations of creep and microearthquakes are coincident with regions where the fluid-bearing Franciscan complex is overlain by the Great Valley sequence and intersects the San Andreas Fault.

However, it should be noted that the profiles at Carrizo Plain and Parkfield do not image the fault zone to the depths at which recent large earthquakes have ruptured (10-15 $\mathrm{km})$. It is possible that the presence of fluids in the upper few kilometers of the fault indicates fluids at depth, but this is clearly not required. Another possibility is that other factors are controlling the seismicity of each fault segment and the zones of low resistivity simply reflect a connected network of fluid-filled cracks maintained by the motion of the fault. In this scenario, the MT surveys are imaging zones of active deformation. New geophysical studies, combined with deep drilling in fault zones are needed to resolve exactly how fluids are related to the earthquake cycle and why different fault segments exhibit such radically different seismic behavior. Specific questions that need to be addressed include:

(a) The geometry of major crustal aquifers and the degree to which they are connected hydrogeologically to major fault zones.

(b) Directly determining the composition of fault-zone fluids in deep wells to allow better porosity estimates. This would further allow for calibration of surface-based geophysical surveys.

(c) Imaging fault-zone resistivity and velocity structure to seismogenic depths.

(d) Resolving three-dimensional resistivity structures to permit unambiguous imaging of structure.

\section{Magnetotelluric Studies of Other Major Strike Slip Faults}

To understand the significance of the San Andreas Fault resistivity models, it is essential to study other strike-slip faults. By expanding the sample size it may be possible to determine if the structure of the San Andreas Fault is typical, or atypical, of major strike-slip faults. Magnetotelluric studies in Japan were the first to show a low resistivity anomaly associated with the near-surface structure of active faults (Electromagnetic Research Group for the Active Fault, 1982). More recently Ritter et al. (2003) studied the Dead Sea Transform in Jordan and imaged an aquifer trapped by the fault which is believed to act as an impermeable seal. No significant fault-zone conductor was found at this location. A strike-slip fault that had been inactive for several million years in Northern Chile was found to have a zone of low resistivity that correlated with the spatial extent of the damaged zone, as mapped by the fracture density (Janssen et al., 2002; Hoffmann-Rothe et al., 2004).
This was inferred to be due to a combination of fracturing and the presence of clay minerals within the rock matrix. It should be noted that in the presence of clay, a porosity estimate based solely on conduction through saline fluids will be an upper estimate. Studies of the North Anatolian Fault in Turkey have revealed major contrasts in resistivity across the fault in the vicinity of the 1999 İzmit earthquake, and further suggest a deeper zone of low resistivity in the lower crust between two diverging fault strands (Tank et $a l ., 2003,2004)$. Bai and Meju (2003) imaged a conductive feature from the surface to mid-crustal depths beneath a major strike-slip fault in southwest China. Wannamaker et al. (2002) describe the geoelectric structure of the South Island in New Zealand, where transpression has resulted in strike-slip motion on the Alpine Fault. A broad zone of low resistivity is imaged southeast of the trace of the Alpine Fault and there is geochemical evidence that the fault may act as a conduit for fluid flow. No zone of low resistivity is observed beneath, or within $5-10 \mathrm{~km}$ to the southeast, of the Alpine Fault trace.

On the northern margin of the Tibetan Plateau, major strike-slip faults accommodate the eastern extrusion of the Tibetan lithosphere (Tapponnier et al., 2001). During the INDEPTH project in 1999, magnetotelluric data were collected across the Kunlun Fault, one of these major strikeslip faults. Detailed studies with closely spaced stations were not made, but the long-period MT data reveal that the Kunlun Fault is coincident with a major transition in lithospheric structure (Unsworth et al., 2004). To the north the lithosphere is relatively resistive to a depth of at least 150 $\mathrm{km}$, and by implication quite cold (Fig. 3). To the south the resistivity is low, implying that the asthenosphere could be present at shallow depths. The MT data do not image any anomalous resistivity features within the inferred shear zone. The low-resistivity layer in the lower crust may represent a channel of lower-crustal flow that accommodates the continued convergence of India and Asia (Clark and Royden, 2000). This interpretation is supported by new MT data collected in Eastern Tibet that reveal a very similar structure with a low resistivity lower crust found just to the west of the Xianshuihe Fault in Sichuan Province (Sun et al., 2003). The Kunlun and Xianshuihe Faults are clearly coincident with major transitions in lithospheric structure, and these magnetotelluric studies of fault zones in Tibet show that regional-scale lithospheric structure may control the location of major fault zones.

An interesting observation is the fact that many major strike-slip faults are located at distances of 50-100 km inland from an ocean-continent margin. This is observed on the San Andreas and North Anatolian faults, and is presumably controlled by the relative mechanical strength of oceanic and continental lithosphere. The Tarim Basin is underlain by oceanic lithosphere, and thus this geometric relationship also holds true for the Altyn Tagh Fault, one of the major strike-slip faults forming the Northern boundary of the Tibetan Plateau.

It is important to clarify how the structures imaged with MT are related to the deformation process. The resistivity images derived from MT exploration reveal the deformation associated with strike-slip motion when it is relatively broad 
and fluids are incorporated. Thus the damaged zone, a halo of fractured rock, is usually the most conspicuous feature in resistivity models, such as those in California and Chile. However, the narrow zone of fault gouge is in some faults just a few centimeters across (Chester et al., 1993) and will not be imaged by any surface-based geophysical technique. This is the case with the Dead Sea transform, where the fault is imaged indirectly through its effect as a fluid-flow barrier, and an extensive damaged zone is absent (Ritter et al., 2004).

There are still insufficient fault-zone studies to generalize what resistivity structures are typically associated with major strike fault zones. Some patterns, however, are emerging as the number of studies increases. A fault-zone conductor is often, but not always, observed in strike-slip faults. The geometry and resistivity of such a feature is controlled by a combination of factors including:

(a) Local geology: A geological setting in which a broad damaged zone developed will be characterized by a relatively wide low resistivity zone. If the fault is located in brittle material, a very narrow zone of gouge may be able to accommodate deformation and any low resistivity zone will be very narrow.

(b) Total offset of the fault: As a fault accumulates offset, the amount of damage will increase and a damaged zone will broaden. The Dead Sea Transform (DST) has accumulated significantly less offset than the San Andreas Fault, a factor that may partially explain the relative absence of low resistivity at that location, i.e. a broad damaged zone has not yet developed in the DST and the width of the damaged zone is still quite narrow.

(c) Hydrogeology. Pore fluids are needed to lower the resistivity in a region of the fault where the rock matrix is fractured. In dry conditions, this may result in relatively high resistivities, even with fracturing. Another complexity may occur if only part of the damaged zone is fluid saturated. For example, at Hollister, seismicity lies at the western edge of the fault-zone conductor. This phenomenon could in part be explained if the active trace acts as a barrier to fluid flow. An expanded discussion of this topic is presented by Ritter et al. (2004).

It is important to further consider the structure of strikeslip faults in the lower crust. An enhanced conductor in the lower crust of a shear zone is suggested by the studies of Tank et al. (2004) on the North Anatolian fault. Jones et al. (1992a) reported a deeper zone of enhanced conductivity on the now inactive Fraser Fault in Western Canada. However, in both these studies, additional MT data would be invaluable to constrain the features in three dimensions and remove the possibility that they are due to the effects of surficial features or three-dimensional effects. Additional evidence for the possible role of fluids in lower crustal earthquake comes from recent MT surveys in Japan (Ogawa et al., 2001; Mitsuhata et al., 2001). In these regions earthquakes occur on the boundary between regions of high and low resistivity. It is suggested that the low resistivity zone represents a source of fluids that migrates into the mechanically stronger, higher resistivity zone.

\section{Imaging Resistivity Structure of Shear Zones in the Mid and Lower Crust with MT}

The fault-zone studies already described have focused on details of the upper-crustal structure and regional scale lithospheric studies. The next stage in fault-zone research with magnetotellurics should address intermediate length scales and elucidate the resistivity structure in the seismogenic zone and ductile lower crust. What variations in electrical resistivity might be expected in these regions? Fault zones in the brittle mid-crust may have limited resistivity signatures owing to the high confining pressures and limited porosity variations. However in the lower crust, the situation may be different. The lower crust is typically a low-resistivity zone. Some authors have proposed that interconnected graphite films may be responsible for this effect (Yardley and Valley, 1997) but this hypothesis has a number of weaknesses (Wannamaker, 2000). An alternative proposal is that aqueous saline fluids are responsible for the low resistivity of the lower crust (Wannamaker, 2000; Jones, 1992b). If the lower crust has a significant fluid content, then shearing could enhance the porosity and permeability, which would further lower the electrical resistivity. Note that lower crustal fluids are a more plausible explanation for low resistivity in regions of active tectonics than stable crust, owing to the fact that deformation enhances and maintains networks of interconnected fluids.

Exhumed shear zones frequently contain mylonite veins. When active these features are fluidized, but too small to be imaged at mid-crustal depths with surface-based geophysical methods. However, a broad zone containing many veins would produce a significant resistivity anomaly. Thermal effects could also lower the electrical resistivity through enhanced solid-state conduction and shear-induced melting. Lithological changes, such as the deposition of graphite or other conductive minerals might also lower the electrical resistivity.

To image such features presents a challenge to all surface-based geophysical methods because (a) the effect of fluids on seismic velocity, density or resistivity will diminish as increased pressure generally reduces porosity variations, and (b) the sensitivity of surface geophysical surveys decreases with increasing depth. These factors are especially true of magnetotelluric methods, since imaging to greater depths requires low frequencies with long wavelengths (skin depths). In addition, there is an inherent trade off between shallow structure and the deeper response of the fault zone. Shallow structure must be accurately determined if deeper structure is to be reliably imaged. Anisotropic electrical structure is likely to be encountered in shear zones and its effects must be evaluated carefully. The long-period MT data reported by Bedrosian et al. (2004) suggest that anisotropic structures may be present at mid-crustal depths beneath the San Andreas Fault zone. This is based on consistent variations in the direction of geoelectric strike directions and the magnetic field transfer functions. However, it is very difficult to distinguish the effects of anisotropy from three-dimensional induction effects.

To investigate what a detailed MT study might achieve, a synthetic inversion study was undertaken. A set of generic geoelectric models was generated, to represent the charac- 


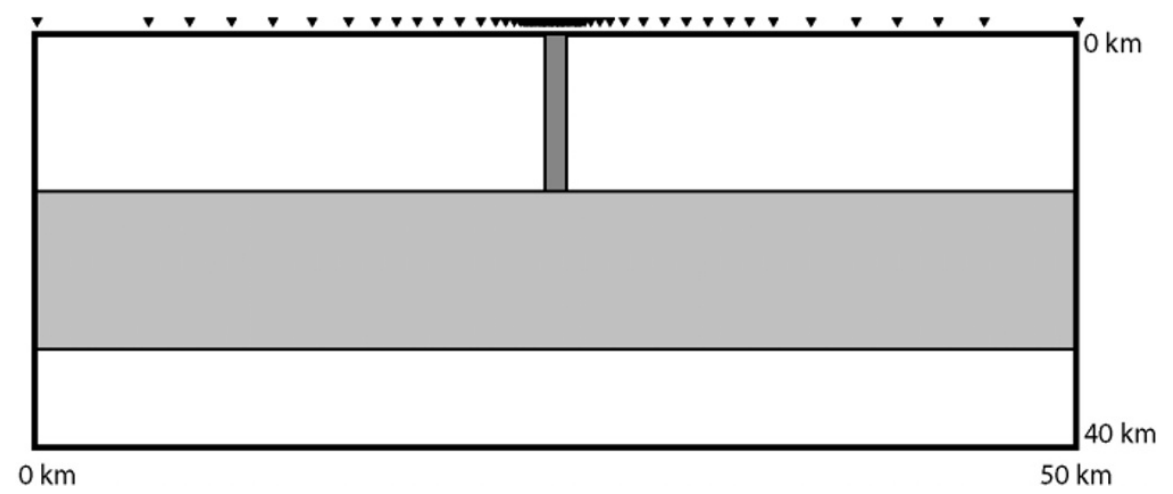

Fig. 4. Geometry of MT profile used in the synthetic inversion study. Spacing was $200 \mathrm{~m}$ in the fault zone, increasing to $10 \mathrm{~km}$ in the outer part of the profile. The profile extended to $100 \mathrm{~km}$ on the left and right sides.

teristic features that might be observed in a major strike-slip fault zone (Figs. 4 and 5). Model $s z-12$ shows a $1 \mathrm{ohm}-$ $\mathrm{m}$ fault zone conductor (FZC) that extends to $5 \mathrm{~km}$, similar to that observed at Parkfield. In this model, the upper crust is uniform and the lower crust is moderately conductive, as observed at many locations (Jones, 1992b). In this model deformation in the lower crust is assumed to occur in a narrow zone that does not alter the resistivity structure. In model $s z-11$ this FZC extends to the lower crust. Models $s z-9$ and sz-10 show alternative scenarios for lower-crustal deformation in which a lower-crustal shear zone (LCSZ) has developed. Fluidization has occurred in a zone $5 \mathrm{~km}$ wide and produced a low resistivity zone (10 ohm-m). The difference between these two models lies in the connection of the FZC to the conductive LCSZ. For each model, synthetic MT data were generated over the frequency band of $10-0.0001 \mathrm{~Hz}$ and Gaussian noise was added. A total of 85 MT stations were used with a spacing that increased from $200 \mathrm{~m}$ within the fault zone, to $10 \mathrm{~km}$ at $100 \mathrm{~km}$ from the surface trace. The inversion models shown in Fig. 5 were obtained by simultaneous inversion of TE and TM mode data (with electric current flowing along and across strike respectively). Inversion models that also included the vertical magnetic field transfer functions are shown as well. These models exhibit a number of features:

(1) The shallow $(5 \mathrm{~km})$ and deep $(15 \mathrm{~km})$ FZC can be distinguished from each other. As expected, this requires the use of the TE mode, which can often be contaminated by 3 -D effects resulting from finite along-strike structures.

(2) The width of the recovered fault-zone conductor increases with depth. This is clearly an artifact, and is a consequence of the decrease in resolution with depth of surface-based geophysical measurements.

(3) The lower crustal shear zone can be imaged if it is not connected to the FZC, although the depth is not recovered accurately. If the FZC extends to $15 \mathrm{~km}$, it is difficult to separate the FZC and LCSZ.

(4) Inclusion of vertical magnetic field transfer functions gives a modest improvement in resolution. However, in field MT data it has been noted that these extra data are valuable. This is likely because the extra data provides some redundancy and compensates for missing, or poor quality MT impedance data. It should also be noted that the transfer functions and impedance data will respond differently to three-dimensional effects, such as a FZC of finite strike length (Wannamaker, 1999).

Major strike-slip faults, however, often juxtapose material of differing resistivity. This is observed at Parkfield where the San Andreas Fault has emplaced high resistivity Salinian granite against lower resistivity rocks of the Franciscan Complex to the east. How will this impact resolution at mid and lower crustal levels? Figure 6 shows synthetic models and inversion results for this scenario. For the specific models considered here:

(1) A LCSZ can be imaged, but cannot be separated from an overlying FZC. Some ambiguity is associated with the depth of this feature.

(2) If the LCSZ is offset from the surface trace, resolution is enhanced when the upper crust is resistive. This occurs since the upper conductor does not screen the lower conductor. However, if the fault was offset to the right, LCSZ could not be imaged, as it will be screened by the conductive upper crust.

(3) Some artifacts are imaged in the resistivity model in the upper $10 \mathrm{~km}$ (for example $s z-3$ ). The most conspicuous is the left-dipping resistive zone that is located to the left of the FZC. This appears to arise from the non-uniform station spacing, and is similar to features observed in field MT data from Parkfield where a dipping conductor was observed at the end of dense portion of each MT profile.

A range of other models were considered, and a range of inversion control parameters were investigated. A low value for the ratio of horizontal to vertical smoothing was required to recover the models shown $(\alpha=0.3)$, reflecting the fact that vertical structures dominate the fault-zone models. This choice effectively permits abrupt lateral changes in the inverted resistivity model. When a higher value was used, unphysical artifacts were observed in the model and the final r.m.s. misfit was unacceptably high. As expected, the study also revealed that higher noise levels will degrade resolution of features shown in the model. Another feature that would complicate real surveys is the presence of low resistivity seawater at the end of the profile. This is an important consideration for studies in western Turkey, California and New Zealand where major bodies of seawater are located close to the fault zones. The influence of the ocean is illustrated by the synthetic inversions in Fig. 7. The model sz-2 was modified by the addition of a $5 \mathrm{~km}$ ocean at distances 


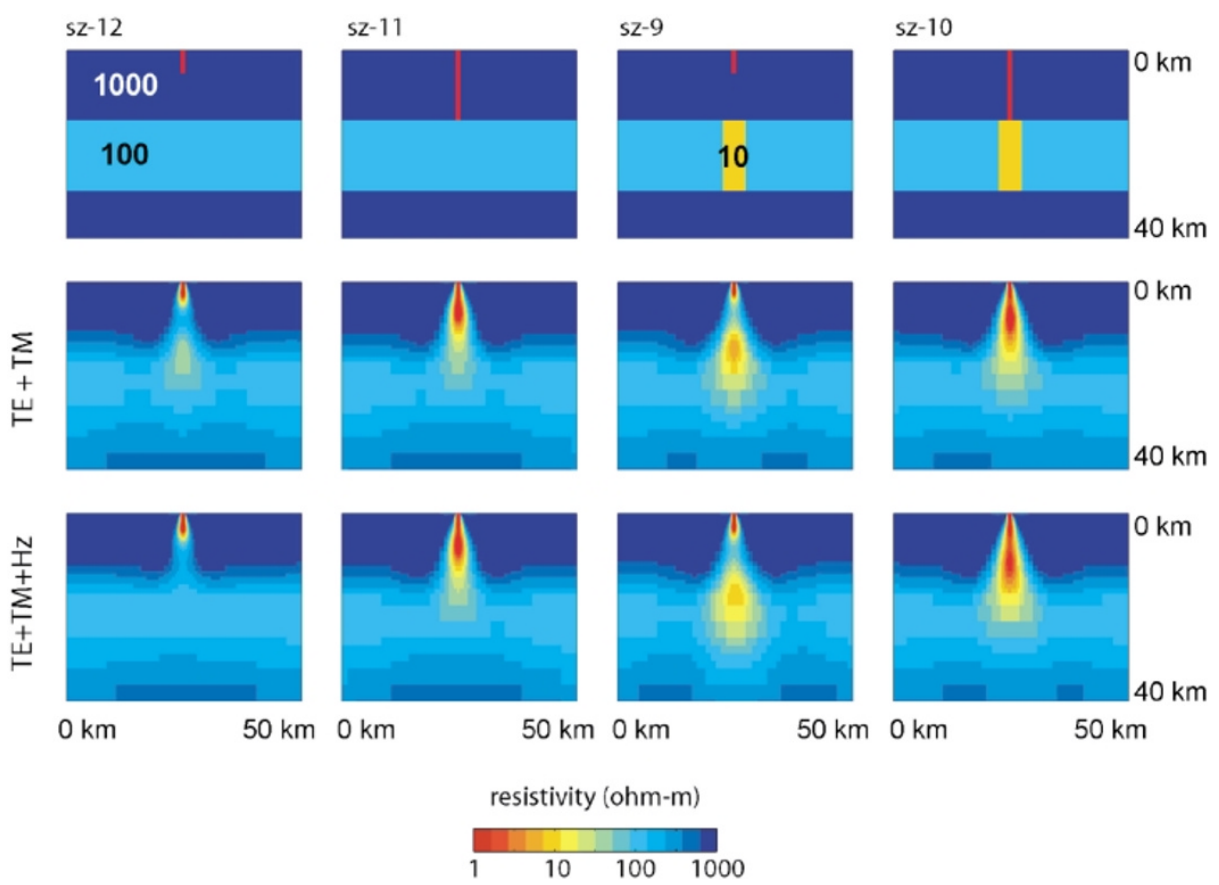

Fig. 5. Possible geoelectric models of a major strike-slip fault. Resistivity values are shown in ohm-m. In the uniform upper crust, the fault is characterized by a $1 \mathrm{~km}$ wide, $1 \mathrm{ohm}-\mathrm{m}$ fault-zone conductor. In the lower crust, a zone of shearing is characterized by a $5 \mathrm{~km}$ wide zone of fluidization with a resistivity of $10 \mathrm{ohm}-\mathrm{m}$. Synthetic MT data were generated for each model and Gaussian noise was then added (5\% in resistivity and an equivalent amount in phase and 0.02 in the magnetic field transfer functions. The data were then inverted using the algorithm of Rodi and Mackie (2001) and all models have a final r.m.s. misfit in the range 0.9-1.1. Regularization parameters used were $\alpha=0.3$ to emphasize vertical structures and $\tau=60$.

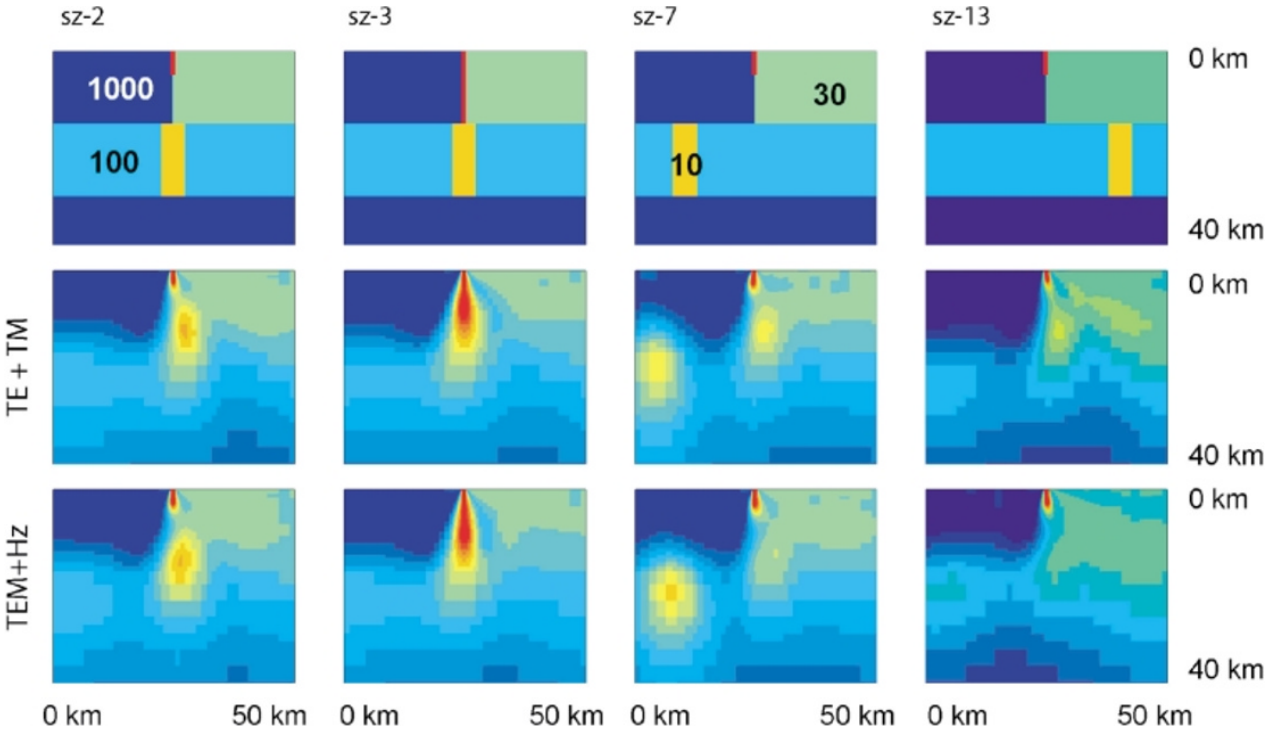

Fig. 6. As in Fig. 5, with a non-uniform upper crust. Resistivity values are shown in ohm-m. Models $s z-2$ and $s z-3$ illustrate a fault zone where deformation in the lower crust occurs beneath the surface trace. In models $s z-7$ and $s z-13$ it is offset by $15 \mathrm{~km}$ to the left and right, respectively.

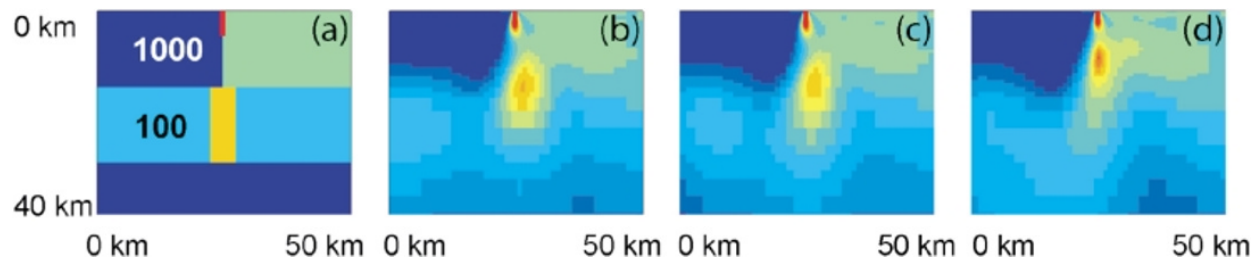

Fig. 7. Effect of the ocean on the inversion process for model sz-2. (a) True model (sz-2 in Fig. 5). (b) Inversion when no ocean is present (c) Inversion when a $5 \mathrm{~km}$ ocean begins $50 \mathrm{~km}$ to the left of the fault zone. Inversion began from $100 \mathrm{ohm}-\mathrm{m}$ halfspace (d) Ocean was included as a fixed parameter in the inversion. All inversions used TE, TM and magnetic field transfer functions with same noise levels as in Figs. 5 and 6. 
of $50 \mathrm{~km}$ and $100 \mathrm{~km}$ from the fault zone. The inversion models are very similar to those obtained in the absence of the ocean. This was observed both when the seawater was included as a fixed parameter and when the inversion began from a uniform halfspace. Note that the effect of the ocean is to place the LCSZ at shallower depths than in model sz-2, even when the ocean is correctly accounted for in the model. This may occur because the ocean acts to concentrate electric currents in the upper crust.

\section{Conclusions}

Over the last decade magnetotelluric measurements have provided new constraints on the upper-crustal structure of major strike-slip faults. Extending these measurements to image the seismogenic zone and lower crust could provide new information about the extent and geometry of deformation in these regions. This will likely require a 3-D magnetotelluric survey, since details of upper-crustal structure must be well defined if lower-crustal, anisotropic structures are to be reliably imaged. The synthetic inversions shown in Figs. 5 and 6 are clearly idealistic and in real surveys there will be complications from three-dimensional structures and non-uniform station spacing. However, these synthetic studies show that information can be determined about lower-crustal structure under favorable circumstances. A location for such a study should be carefully chosen to ensure that the resolution is optimal. Even when the target of the survey is the fault zone at depths of $10-15 \mathrm{~km}$, the station spacing should be approximately $1 \mathrm{~km}$ to accurately image surface structures.

Finally, it is expected that temporal variations in faultzone resistivity structure may occur over the earthquake cycle. Several observations on the San Andreas Fault have given evidence for such changes (e.g. Mazella et al., 1974; Madden et al., 1993), while other monitoring efforts have given negative results. A very careful MT survey will be needed to reliably detect the subtle changes associated with fluid flow during the earthquake cycle.

Acknowledgments. MT data collection in California was funded by the National Science Foundation, the United States Geological Survey and the United States Department of Energy. The INDEPTH magnetotelluric data were collected with support from NSF (Continental Dynamics) and the National Science Foundation of China. MT data analysis was supported by research grants from NSERC and the University of Alberta. PAB acknowledges support form the Alexander von Humboldt Foundation. Ersan Turkoglu is thanked for help with the synthetic inversion study. Reviews by Phil Wannamaker, Oliver Ritter and Yasuo Ogawa (Editor) are gratefully acknowledged. The organizers of the Second International Symposium on Slip and Flow in and below the Seismogenic Zone (University of Tokyo, March 2004) are thanked for the invitation to an excellent workshop.

\section{References}

Anderson, J. L., R. H. Osborne, and D. E. Palmer, Cataclastic rocks of the San Gabriel Fault - an expression of deformation at deeper crustal levels in the San Andreas Fault Zone, Tectonophysics, 98, 209-251, 1983.

Archie, G. E., The electrical resistivity log as an aid in determining some reservoir characteristics, Trans. Am. Inst. Min. Metall. Pet. Eng., 146, 54-62, 1942.

Bai, D. and M. Meju, Deep structure of the Longling-Ruili fault underneath Ruili basin near the eastern Himalayan syntaxis: Insights from MT imaging, Tectonophysics, 364, 135-146, 2003.
Bakun, W. H. and A. G. Lindh, The Parkfield, California, Earthquake Prediction Experiment, Science, 229, 619-624, 1985.

Bedrosian, P. A., M. J. Unsworth, and G. D. Egbert, Magnetotelluric imaging of the creeping segment of the San Andreas Fault near Hollister, Geophys. Res. Lett., 29, 1506, doi:10.1029/2001GL012119, 2002.

Bedrosian, P. A., M. J. Unsworth, G. D. Egbert, and C. H. Thurber, Geophysical images of the creeping segment of the San Andreas Fault: Implications for the role of crustal fluids in the earthquake process, Tectonophysics, 385, doi:10.1016/j.tecto.2004.02.010, 2004.

Blandpied, M. L., D. A. Lockner, and J. D. Byerlee, An earthquake mechanism based on rapid sealing of faults, Nature, 358, 574-576, 1992.

Byerlee, J., Model for episodic flow of high pressure water in fault zones before earthquakes, Geology, 21, 303-306, 1993.

Chester, F. M., J. P. Evans, and R. L. Biegel, Internal structure and weakening mechanisms of the San Andreas Fault, J. Geophys. Res., 98, 771786, 1993.

Clark, M. K. and L. H. Royden, Topographic ooze: Building the Eastern margin of Tibet by lower crustal flow, Geology, 28, 703-706, 2000.

Eberhart-Phillips, D., V. F. Labson, W. D. Stanley, A. J. Michael, and B. D. Rodriguez, Preliminary velocity and resistivity models of the Loma Prieta earthquake region, Geophys. Res. Lett., 17, 1235-1238, 1990.

Electromagnetic Research Group for the Active Fault, Low electrical resistivity along an active fault, J. Geomag. Geoelectr., 34, 103-127, 1982.

Hickman, S., M. Zoback, and W. Ellsworth, Introduction to special section: Preparing for the San Andreas Fault Observatory at Depth, Geophys. Res. Lett., 31, L12S01, doi:10.1029/2004GL020688, 2004.

Hoffman-Rothe, A., O. Ritter, and C. Janssen, Correlation of electrical conductivity an structural damage at a major strike-slip fault in Northern Chile, J. Geophys. Res., 109, doi:10.1029/2004JB003030, 2004.

Irwin, W. P. and I. Barnes, Effect of geologic structure and metamorphic fluids on seismic behavior of the San Andreas Fault system in central and northern California, Geology, 3, 713-716, 1975.

Janssen, C., A. Hoffman-Rothe, S. Tauber, and H. Wilke, Internal structure of the pre-cordilleran fault system (Chile)-insights from structural and geophysical observations, J. Structural Geology, 24, 123-143, 2002.

Johnson, P. A. and T. V. McEvilly, Parkfield seismicity: Fluid-driven?, J. Geophys. Res., 100, 12,937-12,950, 1995.

Jones, A. G., R. D. Kurtz, D. E. Boerner, J. A. Craven, McG. W. Neice, D. I. Gough, J. M. DeLaurier, and R. G. Ellis, Electromagnetic constraints on strike-slip fault geometry-The Fraser River Fault System, Geology, 20, 561, 1992a.

Jones, A. G., Electrical conductivity of the continental lower crust, in Continental Lower Crust, edited by D. M. Fountain, R. J. Arculus, and R. W. Kay, Elsevier, Amsterdam, Chapter 3: pp. 81-143, 1992b.

Mackie, R. L., D. W. Livelybrooks, T. R. Madden, and J. C. Larsen, A magnetotelluric investigation of the San Andreas Fault at Carrizo Plain, California, Geophys. Res. Lett., 24, 1847-1850, 1997.

Madden, T. R., G. A. LaTorraca, and S. K. Park, Electrical conductivity variations around the Palmdale section of the San Andreas Fault Zone, J. Geophys. Res., 98, 795-808, 1993.

Mazella, A. and H. F. Morrison, Electrical resistivity variations associated with earthquakes on the San Andreas Fault, Science, 185, 855-857, 1974.

Mitsuhata, Y., Y. Ogawa, M. Mishina, T. Kono, T. Yokokura, and T. Uchida, Electromagnetic heterogeneity of the seismogenic region of 1962 M6.5 Northern Miyagi Earthquake, northeastern Japan, Geophys. Res. Lett., 28(23), 4371-4374, 2001.

Nadeau, R. M., W. Foxall, and T. V. McEvilly, Clustering and periodic recurrence of microearthquakes on the San Andreas Fault at Parkfield, California, Science, 267, 503-507, 1995.

Ogawa, Y., M. Mishina, T. Goto, H. Satoh, N. Oshiman, T. Kasaya, Y. Takahashi, T. Nishitani, S. Sakanaka, M. Uyeshima, Y. Takahashi, Y. Honkura, and M. Matsushima, Magnetotelluric imaging of fluids in intraplate earthquake zones, NE Japan back arc, Geophys. Res. Lett., 28(19), 3741-3744, 2001.

Ritter, O., T. Ryberg, U. Weckmann, A. Hoffmann-Rothe, A. Abueladas, Z. Garfunkel, and DESERT Research Group, Geophysical images of the Dead Sea Transform in Jordan reveal an impermeable barrier for fluid flow, Geophys. Res. Lett., 30(14), 1741, doi:10.1029/2003GL017541, 2003.

Ritter, O., A. Hoffman-Rothe, P. A. Bedrosian, U. Weckmann, and V. Haak, Electrical conductivity images of active and fossil fault zones, in Microstuctural Evolution and Physical Properties in High Strain Zones, Geological Society of London Special Publications, 2004 (in press).

Rodi, W. and R. L. Mackie, Nonlinear conjugate gradients algorithm for 
2-D magnetotelluric inversion, Geophysics, 66, 174-187, 2001.

Sun, J., G. Jin, D. Bai, and L. Wang, Sounding of electrical structure of the crust and upper mantle along the eastern border of Qinghai-Tibet plateau and its tectonic significance, Science in China (Series D), 46, 243-253, 2003.

Tank, S. B., Y. Honkura, Y. Ogawa, N. Oshiman, M. K. Tunçer, M. Matsushima, C. Celik, E. Tolak, and A. M. Issıkara, Resistivity structure in the western part of the fault rupture zone associated with the 1999 İzmit earthquake and its seismogenic implication, Earth Planets Space, 55, 437-442, 2003.

Tank, S. B., Y. Honkura, Y. Ogawa, M. Matsushima, N. Oshiman, M. K. Tuncer, C. Celik, E. Tolak, and A. M. Isikara, Magnetotelluric imaging of the fault rupture area of the 1999 Izmit (Turkey) earthquake, Physics of the Earth and Planetary Interiors, 2004 (in press).

Tapponnier, P., Xu Zhiqin, F. Roger, B. Meyer, N. Arnaud, G. Wittlinger, and Y. Jingsui, Oblique stepwise rise and growth of the Tibetan Plateau, Science, 294, 1671-1677, 2001.

Thurber, C. and S. Roecker, Two-dimensional seismic image of the San Andreas Fault in the Northern Gabilan Range, central California: Evidence for fluids in the fault zone, Geophys. Res. Lett., 24, 1591-1594, 1997.

Thurber, C., S. Roecker, K. Roberts, M. Gold, L. Powell, and K. Rittger, Earthquake locations and three-dimensional fault zone structure along the creeping section of the San Andreas Fault near Parkfield, CA: Preparing for SAFOD, Geophys. Res. Lett., 31, doi:10.1029/2002GL016004, 2003.

Unsworth, M. J., G. D. Egbert, and J. R. Booker, High Resolution elec- tromagnetic imaging of the San Andreas Fault in Central California, $J$. Geophys. Res., 104, 1131-1150, 1999.

Unsworth, M. J., M. Eisel, G. D. Egbert, W. Siripunarvaporn, and P. A. Bedrosian, Along-strike variations in the structure of the San Andreas Fault at Parkfield, California, Geophys. Res. Lett., 27, 3021-3024, 2000. Unsworth, M. J., W. Wei, A. G. Jones, S. Li, P. A. Bedrosian, J. R. Booker, S. Jin, and M. Deng, Crustal and upper mantle structure of Northern Tibet imaged with magnetotelluric data, J. Geophys. Res., 109, doi:10.1029/2002JB002305, 2004.

Wannamaker, P. E., Affordable magnetotellurics: Interpretation in natural environments, in Three-dimensional Electromagnetics, edited by $\mathrm{M}$. Oristaglio and B. Spies, Geophys. Devel. Ser., no. 7, Soc. Expl. Geophys., pp. 349-374, 1999.

Wannamaker, P. E., Comment on "The petrologic case for a dry lower crust" by B. W. D. Yardley and J. W. Valley, J. Geophys. Res., 105(B3), 6057-6064, 10.1029/1999JB900324, 2000.

Wannamaker, P. E., G. R. Jiracek, J. A. Stodt, T. G. Caldwell, V. Gonzalez, J. McKnight, and A. D. Porter, Fluid generation and pathways beneath an active compressional orogen, the New Zealand Southern Alps, inferred from magnetotelluric data, J. Geophys. Res., 107, 2001JB000186, 2002.

Yardley, B. W. D. and J. W. Valley, The petrologic case for a dry lower crust, J. Geophys. Res., 102, 12173, 1997.

M. Unsworth (e-mail: unsworth@phys.ualberta.ca) and P. A. Bedrosian 